\title{
НЕКОТОРЫЕ ПРОБЛЕМЫ ПРАВОВОГО ПРОТИВОДЕЙСТВИЯ ЭКСТРЕМИСТСКИМ ПРОЯВЛЕНИЯМ В ИНФОРМАЦИОННО- ТЕЛЕКОММУНИКАЦИОННОЙ СЕТИ ИНТЕРНЕТ
}

Современное общество характеризуется высокой степенью развития информационно-коммуникационных технологий, но данный процесс имеет как положительные, так и отрицательные стороны. Так, информационные технологии и всемирная сеть Интернет облегчают обмен информацией гражданами и их объединениями в любое время, в любом месте, предоставляют возможности для интеллектуального развития, облегчают доступ к информации.

Однако в современных условиях, информационные технологии широко используются экстремистскими и террористическими организациями в своей деятельности. Как средство распространения экстремистских материалов, сеть Интернет обладает определенными особенностями. Так, он состоит из совокупности сетей, имеющих разное географическое расположение. А информация, которая размещается во всемирной паутине, становится доступной для неограниченного круга лиц, в разных частях света. Причем и лица, разместившие информацию, и лица, ее пользующиеся могут сохранять анонимность. Кроме того, в связи с отсутствием географических рамок, ограничение доступа к информации или блокировка сайта, не избавляют от проблемы размещения такой информация в другом месте. Таким образом, на первый план выходят проблемы установления лиц, разместивших информацию экстремистской направленности в сети Интернет, а также установления владельца сайта, на котором были размещены данные материалы.

По мнению авторов, решить проблему противодействия террористическим и экстремистским организациям довольно сложно. Однако эффективность работы в данном направлении во многом зависит от действенной и современной правовой базы. Особая роль в блоке нормативно - правовых актов в сфере противодействия экстремизму принадлежит нормам уголовного и административного права, которые в свою очередь обладают рядом недостатков. Авторы отмечают необходимость разработки общегосударственной комплексной программы, охватывающей не только правоохранительный, но и политический, социальный, экономический, правовой, идеологический, пропагандистский, информационный, оперативно-розыскной и другие аспекты.

Ключевые слова: противодействие экстремизму информационно-телекоммуникационная сеть, сеть Интернет, информационное общество, экстремизм, терроризм, право, законодательное регулирование

Z. T. Zoloeva, B. G. Koybaev

\section{SOME PROBLEMS OF LEGAL COUNTERACTION TO EXTREMIST MANIFESTATIONS IN THE INFORMATION-TELECOMMUNICATION NETWORK INTERNET}

Modern society is characterized by a high degree of development of information and communication technologies, but this process has both positive and negative sides. Thus, information technology and the world wide web facilitate the exchange of information by citizens and their associations anytime, anywhere, provide opportunities for intellectual development, facilitate access to information.

However, in modern conditions, information technology is widely used by extremist and terrorist organizations in their activities. As a means of disseminating extremist materials, the Internet has certain characteristics. Thus, it consists of a set of networks with different geographical location. And the information that is posted on the world wide web, becomes available to an unlimited number of people in different parts of the world. Moreover, both the person who posted the information and the person who uses it can remain anonymous. In addition, due to the lack of geographical boundaries, limited access to information or blocking the site, do not eliminate the problem of placing such infor- mation elsewhere. Thus, the problems of identifying people who posted extremist information on the Internet, as well as the owner of the site on which these materials were posted, come to the fore.

According to the authors, it is quite difficult to solve the problem of countering terrorist and extremist organizations. However, the effectiveness of work in this direction largely depends on the effective and modern legal framework. A special role in the block of normative legal acts in the sphere of countering extremism belongs to the norms of criminal and administrative law, which in turn has a number of shortcomings. The authors note the need to develop a comprehensive national program covering not only law enforcement, but also political, social, economic, legal, ideological, propaganda, information, operational-investigative and other aspects.

Key words: counteraction to extremism, information and telecommunication network, Internet, information society, extremism, terrorism, law, legislative regulation. 
В настоящее время наблюдается рост преступлений экстремистской направленности. Видится, что одной из причин, способствующих распространению экстремизма в РФ выступает развитие информационно-коммуникационных технологий в целом и Интернета в частности. Так при помощи Интернета осуществляется вербовка новых участников экстремистских формирований и распространение экстремистских материалов В этой связи была ужесточена уголовная ответственность за призывы к экстремизму, а в КоАП были внесены новые статьи.

Еще одной причиной роста преступлений экстремистской направленности выступают активные миграционные процессы. В связи, с чем во многих субъектах РФ, где зафиксирован приток мигрантов, наблюдается рост напряженности и угроза проявления экстремизма

В современных условиях возможности Всемирной сети по распространению информации и информационному воздействию, практически равны, возможностям традиционных средств массовой информации, в связи с чем, возможности сети Интернет, широко используются террористическими и экстремистскими формированиями в целях пропаганды национальной и религиозной нетерпимости.

Для преступлений, совершаемых в сети Интернет, характерна высокая степень латентности, обусловленная применением механизмов обеспечения анонимности, что зачастую позволяет правонарушителям избегать мер ответственности и повторно совершать правонарушения и преступления в исследуемой сфере. Важно отметить, что в современных условиях развития информационного общества более $90 \%$ из рассмотренных преступлений экстремистского характера, совершаются с использованием сети Интернет.

Кроме того, важно отметить, что преступления экстремистской направленности, совершаемые в сети Интернет, зачастую имеют трансграничный характер, когда преступник и объект преступного посягательства находятся под юрисдикцией различных государств. Совершение преступного деяния, как правило, осуществляется дистанционно, причем часть таких действий может выполняться в автоматизированном режиме. Следы преступных действий в сети Интернет распределяются по множеству объектов, и характеризуются отсутствием четко выраженного места преступления.

Кроме того, важно отметить нестандартность, сложность, многообразие и частоту обновления способов совершения преступлений и применяемых при этом специальных средств. Глобализация, сопровождающаяся формированием наднациональных институтов, обслуживающих интересы отдельных корпоративных групп и стран, разрушительно воздействует на государственный и общественный порядки, действующие в пределах конкретного национального пространства $[5$, с. 65$]$.

В этих условиях, происходит увеличение потенциала экстремистских организаций, действующих по принципу сетевой организации. Дпя данных организаций характерно наличие единых центров управления [7]

Экстремистские сообщества постоянно расширяют сфреру своего информационного пространства, и в тоже время прививают собственные установки широкой аудитории. Таким образом, инфрормационный экстремизм, может выступать в качестве подготовительного этапа для других, в том числе и крайних форм экстремизма, и формировать благоприятную среду для распространения экстремистских убеждений. Субъектом информационного экстремизма может стать как экстремистская группа, так и одно лицо. А основным методом информационного экстремизма выступает речевое воздействие.

Для России угрозу представляют ресурсы, направленные на осуществление информационной и финансовой поддержки террористических организаций, в том числе и международных. Такие ресурсы зачастую содержат призывы к совершению актов терроризма, а также пропагандируют, религиозную нетерпимость, межнациональную рознь и сепаратизм.

В сети Интернет постоянно увеличивается количество сайтов, на которых распространяется информация, способствующая развитию экстремизма. Примечательно, что большая часть интернет - адресов таких сайтов зарегистрирована в других государствах. Справочные ресурсы, напрямую не призывающие к противоправной деятельности, но подразумевающие ее совершение, вызывают особую озабоченность правоохранительных органов России. Так как на таких ресурcax распространяется информация об изготовлении взрывчатых веществ, способах получения ядов, сборки самодельных взрывных устройств и т.д. Как правило, такие ресурсы недолговечны, часто меняют доменные имена и довольно многочисленны. Решению проблемы распространения экстремизма в сети Интернет будет способствовать унисрикация и совершенствование законодательства РФ, в сфере распространения информации в телекоммуникационных сетях общего пользования.

Таким образом, в современных условиях, наряду с основными проявлениями экстремизма политическим, национальным и религиозным, выделяют и информационный экстремизм.

Как справедливо отмечает А. В. Карягина, основным “оружием» информационного экстремизма является не нивелирование ценностей и символов существующего строя, а деформация важнейших коммуникационных связей [4, с. 106], в целях развития хаоса в информационном обществе.

Кроме того, информационный экстремизм имеет еще одно проявление, связанное с информационным воздействием на широкий круг лиц при помощи средств массовой информации. Это наносит большой вред нашей государственности, подрывает основы правовой культуры, в которой правопослушание играет ведущую роль [13, с. 25-33].

По нашему мнению, в современных условиях характеризующихся развитием информационного общества и глобализацией, проблема инфор- 
мационного экстремизма стоит особенно остро. Во многом это связано с возможностью манипулирования индивидуальным и общественным сознанием, что в конечном итоге может привести к возникновению информационных войн. Все это, выводит на новый уровень проблему обеспечения информационной безопасности.

Важно отметить, что в настоящее время происходит изменение структуры экстремистских группировок. Так, сегодня за счет развития новых информационно-коммуникационных технологий, иерархическая структура экстремистских организаций, возглавляемых одним лицом, сменилась на сетевую, в рамках которой могут существовать и несколько лидеров. Все это усложняет работу по выявлению такого рода экстремистских организаций.

Особое место в деле противодействия экстремизму в сети Интернет занимает действенная правовая база. В настоящее время в Российской Федерации происходит интенсивное развитие и совершенствование организационно-правовых основ противодействия экстремизму. В связи, с чем на проблематику противодействия экстремизму неоднократно обращали внимание Президент Российской Федерации, Генеральный прокурор, Директор ФСБ, Министр внутренних дел России. Так, выступая на заседании коллегии Министерства внутренних дел 9 марта 2017 года, Президент В. В. Путин выделил противодействие экстремизму в качестве одной из важнейших задач государства. Все это свидетельствует об актуальности исследования вопросов противодействия экстремистским проявлениям на современном этапе развития, как в Российской Федерации в целом, так и в ее регионах.

Как известно, правовая база в сфере противодействия экстремистским проявлениям состоит из норм международного права, федеральных нормативных актов и нормативно-правовых актов субъектов Российской Федерации.

Федеральный закон от 25.07.2002 №114-Ф3 «О противодействии экстремистской деятельности» устанавливает следующие основные меры противодействия исследуемому явлению:

- принятие профилактических мер, направленных на предупреждение экстремистской деятельности, в том числе на выявление и последующее устранение причин и условий, способствующих осуществлению указанной деятельности;

- выявление, предупреждение и пресечение экстремистской деятельности общественных и религиозных объединений, иных организаций, физических лиц [11].

Стратегия противодействия экстремизму в Российской Федерации до 2025 года, конкретизирующая положения Федерального закона от 25 июля 2002 г. №114-Ф3 «О противодействии экстремистской деятельности», Указа Президента Российской Федерации от 12 мая 2009 №537 «О Стратегии национальной безопасности Российской Федерации до 2020 года», указывает что националистический, религиозный и политический являются наиболее опасными видами экстремизма. В Стратегии отмечается активное использование экстремистскими и террористиче- скими организациями информационно-телекоммуникационных сетей, включая сеть «Интернет», в целях привлечения новых участников, распространения экстремистской идеологии, а также координации совершения преступных деяний экстремистского характера [10]

В качестве одного из направлений политики государства в сфере противодействия экстремизму Стратегия называет необходимость совершенствования правовых основ в области противодействия экстремистским проявлениям (производству и распространению экстремистских материалов), а также в телекоммуникационных сетях.

Правовое регулирование интернет-контента, основывается на федеральных законах «О связи», «Об информации, информатизации и защите информации», “О средствах массовой информации» и др.

Особое значение среди перечисленных законов имеет Ф3 «Об информации, информатизации и защите информации". Так, Закон устанавливает возможность ограничения Роскомнадзором доступа к информационным ресурсам, содержащим призывы к массовым беспорядкам, осуществлению экстремистской деятельности, на основе обращения Генерального прокурора Российской Федерации либо его заместителей [12].

Федеральный закон «О средствах массовой информации» установил, что использование СМИ с целью совершения преступных деяний, а также с целью распространения материалов, содержащих публичные призывы к осуществлению террористической деятельности или публично оправдывающих терроризм, других экстремистских материалов, а также материалов, пропагандирующих порнографию, культ насилия и жестокости, и материалов, содержащих нецензурную брань не допустимы [2]

В деле противодействия экстремистским проявлениям важное значение имеют нормы уголовного и административного законодательства. В частности, это статьи, устанавливающие ответственность за: организацию деятельности террористической организации и участие в деятельности такой организации (205.5 УК,); призывы к экстремистской деятельности (280 УК); возбуждении ненависти либо вражды (282 УК); за публикации, которые могут быть отнесены к деятельности экстремистского сообщества или запрещенной организации (282.1 УК); за организацию деятельности экстремистской организации (282.2 УК); за финансирование экстремизма (282.3 УК) и др.

Подтверждением нарастающему напряжению в правоприменительной практике, выступает и формирующаяся судебная практика, направленная на совершенствование подхода к вопросам понимания преступного деяния и наступления ответственности за его совершение. В рамках данного исследования интерес представляет анализ Постановления Пленума Верховного Суда РФ от 03.11.2016 №41 «О внесении изменений в постановления Пленума Верховного Суда Российской Федерации от 9 февраля 2012 года №1 «О некоторых вопросах судебной практики по уголов- 
ным делам о преступлениях террористической направленности» и от 28 июня 2011 года №11 «О судебной практике по уголовным делам о преступлениях экстремистской направленности».

Из положений, касающихся ст. 282 УК, важнейшим является разъяснение, устанавливающее, что возбуждение ненависти в том или ином проявлении - это не любые негативные высказывания, а именно призывы к противоправным действиям, и это необходимо учитывать при рассмотрении судами, следователями уголовных дел и квалификации деяний.

Другим важным разъяснением является позиция Верховного суда России по вопросу об оценке публикаций в сети Интернет, которая гласит, что при решении вопроса о направленности действий лица, разместившего какую-либо информацию либо выразившего свое отношение к ней в сети "Интернет» или иной информационно-телекоммуникационной сети, на возбуждение ненависти либо вражды, а равно унижение достоинства человека либо группы лиц следует исходить из совокупности всех обстоятельств содеянного и учитывать, в частности, контекст, форму и содержание размещенной инсрормации, наличие и содержание комментариев или иного выражения отношения к ней [6].

Федеральным законом от 28.06.2014 года №179-Ф3 “О внесении изменений в отдельные законодательные акты Российской Федерации» в 4.2 ст. 280 УК РФ и в ч. 1 ст. 282 УК РФ были внесены изменения, предусматривающие в диспозиции указанных статей уголовную ответственность за призывы к осуществлению экстремистской деятельности, а также действия, направленные на возбуждение ненависти либо вражды, на унижение достоинства человека либо группы лиц по признакам пола, расы, национальности, языка, происхождения, отношения к религии, а равно принадлежности к какой-либо социальной группе, совершенные публично или с использованием средств массовой информации либо информационно-коммуникационных сетей, в том числе сети Интернет.

Важно отметить, что до принятия указанного Закона, конкретизации относительно информационно-коммуникационных сетей, в том числе сети Интернет, в уголовном законодательстве Российской Федерации не было. Ранее запрещалось распространение экстремистских призывов только в средствах массовой информации, к которым информационно-коммуникационные сети не относились.

Анализ судебной практики показывает, что наиболее часто преступления данной категории совершаются посредством использования социальных сетей. Кроме того, анализ практики позволяет сделать вывод, о том, что в большинстве случаев размещение высказываний экстремистского характера в сети Интернет, происходит в результате дискутирования пользователями острых тем в различных группах социальных сетей.

В 2017 году по ст. 282 ч.1 УК был осужден 461 человек, большая часть приговоров была вынесена за высказывания, сделанные в онлайн режи- ме [8]. Так, в соответствии с докладом Генерального прокурора РФ Совету Федерации, в стране наблюдается рост преступлений связанных с осуществлением призывов к нарушению территориальной целостности, общественного порядка и безопасности на $5 \%$, осуществляемых в Интернете (пресечено 1500 нарушений) [1]. В соответствии с докладом, в 2017 году осуществлена блокировка более 2000 сайтов, осуществлявших распространение призывов к участию в несогласованных митингах и иных публичных мероприятиях, а с 60000 . интернет-ресурсов удалена противозаконная информация. Таким образом, на первый план выходят преступления, связанные с пропагандой идей национального, религиозного и расового превосходства посредством использования сети Интернет. Все это требует соответствующей реакции со стороны правоохранительных и органов.

Нормы, закрепляющие административную ответственность за правонарушения в исследуемой соере содержатся в Кодексе об административных правонарушениях - это ст. 20.3 «Пропаганда и публичное демонстрирование нацистской атрибутики» и ст. 20.29 КоАП РФ «Производство и распространение экстремистских материалов». Только за прошедший год к административной ответственности по ст. 20.29 КоАПа России были привлечены шесть жителей Северной Осетии, разместившие в сети Интернет материалы экстремистского характера [9]

По нашему мнению, существует необходимость, закрепления на законодательном уровне запрета использования средств обеспечения анонимности в сети Интернет. Видится, что такие меры позволят значительно повысить эффективность реализуемых мероприятий по выявлению и пресечению фактов распространения экстремистских материалов.

Так, 16 апреля 2018 года на территории России начался процесс ограничения доступа к мессенджеру Telegram. C 2015 года Telegram заблокирован также в Китае. Об отдельных случаях перебоев в доступе к сервису сообщали пользователи в Иране, Пакистане, Индонезии, Саудовской Аравии, и Бахрейне [3].

На сегодняшний день, одной из важных проблем выступает недостаточное нормативно-правовое регулирование в рамках международного взаимодействия государств в сфере противодействия экстремизму и терроризму в информационно-коммуникационном пространстве. Проблема осложняется использованием государствами различных, как правило, отличные друг от друга, подходов к нормативно-правовому регулированию антиэкстремистской деятельности. Что конечно не способствует эффрективному сотрудничеству в борьбе с экстремизмом в сети Интернет.

По нашему мнению, было бы целесообразным принятие соответствующих документов международного уровня, которые бы закрепили, как правовой статус международного информационного пространства, так и механизмы урегулирования споров, и вопросы оказания правовой помощи. 
5 июня 2017 г Правительство РФ представило Президенту РФ предложение о подписании Конвенции Шанхайской организации сотрудничества по противодействию экстремизму, которое было одобрено. В соответствии со ст. 7 Конвенции, стороны разрабатывают и осуществляют меры на национальном уровне по противодействию экстремизму, которые могут включать, в том числе меры по:

- усилению пропагандистской деятельности в ссрере противодействия экстремизму и контрпропагандистскую работу против распространения экстремистской идеологии, в том числе в средствах массовой информации (СМИ) и сети «Интернет»;

- мониторингу СМИ и сети «Интернет» в целях своевременного выявления и пресечения распространения экстремистской идеологии;

- ограничению доступа к экстремистским материалам, размещенным в информационно-телекоммуникационных сетях.

Несомненно, принятие Конвенции позволит повысить эфффективность борьбы с распространением экстремизма в сети Интернет. Однако Конвенция еще не принята, кроме того она носит региональный характер. По нашему мнению, существует необходимость разработки универсального международного документа, который бы регулировал борьбу с экстремизмом в сети «Интернет».

Правоохранительными органами осуществляются организационные и практические мероприятия, преследующие цель повышения эффективности деятельности по противодействию экстремизму. Однако в процессе расследования уголовных дел данной категории возникают коллизионные моменты, связанные с тем, что различными экспертными учреждениями, используются различные методики оценки экстремистских материалов, что не позволяет сформировать единообразную практику, в этой части. Кроме того, нередко заключения по одному и тому же материалу носят взаимоисключающий характер.

По состоянию на май 2018 года в федеральный список экстремистских материалов входит 4450 наименований.

В качестве еще одной проблемы можно выделить длительный период проведения психолого-лингвистических исследований и судебных экспертиз, которые, как правило, проводятся больше 6 месяцев. Несомненно, это отрицательно сказывается на качестве следствия. Во многом эта ситуация обусловлена нехваткой специализированных экспертных учреждений.

Проблема противодействия проявлениям экстремизма в сети Интернет имеет и региональный аспект. Так, на территории Республики Северная Осетия - Алания по данным портала правовой статистики с 2014 года зарегистрировано 43 преступления экстремистской направленности, по которым были возбуждены и расследовались уголовные дела (2014-8, 2015-10, 2016-10, 2017-15). Необходимо отметить, что все расследованные уголовные дела о преступлениях экстремистского характера связаны с выявлением фактов совершения преступлений в социальных сетях, комментариях и обсуждениях информации в блогах. Большая часть преступлений была совершена путем публичного комментирования тех или иных событий в форме, содержащей признаки действий, направленных на возбуждение ненависти либо вражды, а также на унижение достоинства человека либо группы лиц по признакам пола, расы, национальности, языка, происхождения, отношения к религии, а равно принадлежности к какой-либо социальной группе

Анализ особенностей совершенных преступлений и личностей преступников показывает, что преступления зачастую совершаются молодыми людьми с неустановившимися взглядами на жизнь и в отношении конкретных фрактов. Кроме того, для лиц, совершивших преступления, исследуемой направленности, характерна некая инфантильность в рассуждениях по поводу совершенного деяния, которое по их глубокому убеждению не может быть преступным. Видится, что это может свидетельствовать о недостаточном присутствии в их жизни и окружающей среде нормативов и установок, ориентирующих на законопослушность.

Подводя итог, следует отметить, что повышению эффективности проводимой политики в сфере противодействия экстремизму, в том числе и в сети Интернет, по нашему мнению, будет способствовать разработка общегосударственной комплексной программы, охватывающей не только правоохранительный, но и правовой, оперативно-розыскной и другие аспекты. Однако важно учитывать, что только силами государства противостоять этому деструктивному явлению современности практически невозможно, а потому необходима поддержка со стороны граждан и институтов гражданского общества.

Кроме того, в современных условиях, сопровождающихся развитием глобализации и информационного общества, видится важным, постоянное совершенствование правовых норм в сфере противодействия экстремистским проявлениям на основе налаживания действенных международно-правовых механизмов.

\section{Литература}

1. Доклад Генерального прокурора Российской Федерации Ю.Я. Чайки на заседании Совета Федерации Федерального Собрания Российской Федерации URL: https://genproc.gov.ru/smi/news/genproc/news-1366820/ (Дата обращения 25.05.2018).

2. Закон РФ от 27.12.1991 N 2124-1 (ред. От 18.04.2018) «О средствах массовой информации» // Российская газета. 08.02.1992. №3.

3. История блокировки Telegram в России. URL: http://tass.ru/info/5121968 (Дата обращения 20.02.2018)

4. Карягина А. В. Информационный экстремизм в современном государственно-правовом пространстве. //Философия права. 2010. №4. С. 105-107. 
5. Марченко М. Н. Глобализация и ее воздействие на современное национальное государство (методологический аспект) // Теоретико-методологические проблемы права. М.: Зерцало-М, 2007. С.65.

6. Постановление Пленума Верховного Суда РФ от 03.11.2016 № 41 «О внесении изменений в постановления Пленума Верховного Суда Российской Федерации от 9 февраля 2012 года № 1 «О некоторых вопросах судебной практики по уголовным делам о преступлениях террористической направленности» и от 28 июня 2011 года № 11 «О судебной практике по уголовным делам о преступлениях экстремистской направленности»// Российская газета. 16.11.2016. №259.

7. Принципы борьбы с экстремизмом в сети и вне ее будут одинаковыми / Официальный сайт информационного портала SecurityLab.ru URL: http:// www.securitylab.ru/news.html (Дата обращения: 25.05.2018)

8. Сводные статистические сведения о состоянии судимости в России за 2017 год URL: http://www.cdep.ru/index. php?id=79\&item=4572 (Дата обращения: 25.05.2018)

9. Северная Осетия. 2017. 6 декабря.

10.Стратегия противодействия экстремизму в Российской Федерации до 2025 года (утв. Президентом РФ 28.11.2014 N Пp-2753) URL: http://www.consultant.ru/cons/cgi/online.cgi?req=doc\&base=LAW\&n=286904\&rnd=EAE6B70A3D85EED4 5A40A422F92F800F\#03968254353877261 (Дата обращения 20.02.2018)

11. Федеральный закон от 25.07.2002 № 114-Ф3 (ред. От 23.11.2015) «О противодействии экстремистской деятельности) // Собрание законодательства РФ. 29.07.2002. № 30. Ст. 3031

12. Федеральный закон от 27.07.2006 № 149-Ф3 (ред. От 23.04.2018) «Об информации, информационных технологиях и о защите информации» (с изм. И доп., вступ. В силу с 30.06.2018) // Собрание законодательства РФ. 31.07.2006. № 31 (1 ч.). Ст. 3448.

13. Чеджемов С. Р. Правопослушание как результат правовой аккультурации на юге России до революционных событий 1917 г. (по материалам истории осетинского народа). // Журнал российского права 2017. №11 (251). С. 25-33.

\section{References}

1. Doklad General'nogo prokurora Rossiyskoy Federatsii U. Ya. Chayki na zasedanii Soveta Federatsii Federal'nogo Sobraniya Rossiyskoy Federatsii (Report of the Prosecutor General of the Russian Federation Yu. Y. Chaika at the Meeting of the Federation Council of the Federal Assembly of the Russian Federation).URL: https://genproc.gov.ru/smi/news/genproc/ news-1366820/ (Accessed: 25.05.2018) (In Russian).

2. Zakon RF "O sredstvakh massovoy informatsii) (Law of the Russian Federation No. 2124-1 of 27.12.1991 (as Amended on 18.04.2018) "On the Mass Media») // Rossiyskaya Gazeta. No.3. 08.02.1992. (In Russian).

3. Istoriya blokirovki Telegram v Rossii (The History of Blocking Telegram in Russia.) URL: http: //tass.ru/info/5121968 (Accessed: 02.20.2013). (In Russian).

4. Karyagina A. V. Informatsionnyy ekstremizm v sovremennom gosudarstvenno-pravovom prostranstve. (Information Extremism in the Modern State-Legal Space) // Filosofiya prava. 2010. No.4. P. 105-107. (In Russian)

5. Marchenko M. N. Globalizatsiya i yeye vozdeystviye na sovremennoye natsional'noye gosudarstvo (metodologicheskiy aspekt) (Globalization and Its Impact on the Modern National State (Methodological Aspect)) // Teoretiko-metodologicheskiye problemy prava. M.: Zercalo-M, 2007. P. 65. (In Russian).

6. Postanovleniye Plenuma Verkhovnogo Suda RF ot 03.11.2016 № 41 «O vnesenii izmeneniy v postanovleniya Plenuma Verkhovnogo Suda Rossiyskoy Federatsii ot 9 fevralya 2012 goda № 1 «O nekotorykh voprosakh sudebnoy praktiki po ugolovnym delam o prestupleniyakh terroristicheskoy napravlennosti» i ot 28 iyunya 2011 goda № 11 «O sudebnoy praktike po ugolovnym delam o prestupleniyakh ekstremistskoy napravlennosti) (Resolution of the Plenum of the Supreme Court of the Russian Federation of 03.11.2016 No. 41 "On Amending the Decisions of the Plenum of the Supreme Court of the Russian Federation of February 9, 2012 No. 1》 On Certain Issues of Judicial Practice in Criminal Cases on Crimes of a Terrorist Attitude "and dated June 28, 2011 year № 11» On Judicial Practice in Criminal Cases on Crimes of an Extremist Direction») // Rossiyskaya Gazeta. No. 259. 11.16.2016. (In Russian).

7. Printsipy bor'by s ekstremizmom $v$ seti i vne yeye budut odinakovymi (The Principles of Fighting Extremism in the Network and Outside it Will be the Same / Official Site of the Information Portal SecurityLab.ru) URL: http: // www.securitylab. ru/news.html (Accessed: 25.05.2018). (In Russian).

8. Svodnyye statisticheskiye svedeniya o sostoyanii sudimosti v Rossii za 2017 god. (Summary Statistics on Criminal Status in Russia for 2017) URL: http://www.cdep.ru/index.php?id=79\&item=4572 (Accessed: 25.05.2018) (In Russian).

9. Severnaya Osetiya. 06 dekabrya 2017 goda.(North Ossetia. December 06, 2017).

10. Strategiya protivodeystviya ekstremizmu v Rossiyskoy Federatsii do 2025 goda (Strategy of Counteraction to Extremism in the Russian Federation until 2025 (Approved by the President of the Russian Federation on 28.11.2014 N Pr-2753) URL: http://www.consultant.ru/cons/cgi/online.cgi?req=doc\&base=LAW\&n= 286904 \& $\mathrm{rnd}=$ EAE6B70A3D85EED45A40A422F92F $800 \mathrm{~F} \# 03968254353877261$ (Accessed: 20.02.2018). (In Russian).

11. Federal'nyy zakon ot 25.07.2002 № 114-FZ (red. ot 23.11.2015) «O protivodeystvii ekstremistskoy deyatel'nosti») (Federal Law No. 114-FZ of 25 July 2002 (as Amended on 11/23/2015) "On Counteracting Extremist Activity") // Sobraniye zakonodatel'stva RF. 29.07.2002. No. 30. Art. 3031. (In Russian).

12. Federal'nyy zakon ot 27.07.2006 № 149-FZ (red. ot 23.04.2018) «Ob informatsii, informatsionnykh tekhnologiyakh i o zashchite informatsii) (Federal Law No. 149-FZ of July 27, 2006 (as Amended on April 23, 2013) "On Information, Information Technologies and Information Protection" (as Amended and Supplemented, Effective as of June 30, 2013)) // Sobraniye zakonodatel'stva RF. 31.07.2006. No. 31 (Part 1). Art. 3448. (In Russian).

13. Chedgemov S. R. Pravoposlushaniye kak rezul'tat pravovoy akkul'turatsii na yuge Rossii do revolyutsionnykh sobytiy $1917 \mathrm{~g}$. (po materialam istorii osetinskogo naroda) (Righteous Obedience as a Result of Legal Acculturation in the South of Russia prior to the Revolutionary Events of 1917 (Based on the History of the Ossetian People)) // Zhurnal rossiyskogo prava 2017. No. 11 (251). P. 25-33. (In Russian). 